\title{
Maternal influences on offspring size variation and viability in wild European lobster Homarus gammarus
}

\author{
Even Moland ${ }^{1,2, *}$, Esben Moland Olsen ${ }^{2}$, Nils Christian Stenseth ${ }^{1,2}$ \\ ${ }^{1}$ Centre for Ecological and Evolutionary Synthesis (CEES), Department of Biology, University of Oslo, PO Box 1066, \\ Blindern, 0316 Oslo, Norway \\ ${ }^{2}$ Institute of Marine Research, Nye Flødevigvei 20, 4817 His, Norway
}

\begin{abstract}
In many marine species, large females tend to produce more robust offspring than small females. However, knowledge on maternal influences in decapod crustaceans is limited. This is unfortunate since many decapod populations are being intensively harvested and show signs of 'juvenescence', i.e. the loss of large (and presumably old) individuals. In this study, we quantified maternal influences in European lobster Homarus gammarus from Skagerrak, southern Norway. Historical lobster catches in Skagerrak were substantial but the stock has suffered a major decline over the past 30 to $40 \mathrm{yr}$ and is currently red listed as near threatened according to the IUCN (International Union for Conservation of Nature) criteria. We studied eggs and larvae from wild-caught ovigerous females ranging in carapace length from 79 to $152 \mathrm{~mm}(\mathrm{n}=45)$. Mean egg size increased while sibling size variation decreased significantly with increasing maternal size. Mean larval size at hatching was closely linked to both maternal size and mean egg size. A laboratory experiment showed a weak but significant nonlinear increase in pelagic larval survival with increasing mean egg size in the absence of food. These findings suggest that maternal influences on offspring quality could be a significant source of variation in lobster recruitment. Consequently, maternal influences could be an important source of error in fisheries science and management if they are assumed to be absent or unimportant.
\end{abstract}

KEY WORDS: Maternal effects $\cdot$ Decapoda $\cdot$ Sibling size variation $\cdot$ Egg size $\cdot$ Survival $\cdot$ Early life history Resale or republication not permitted without written consent of the publisher

\section{INTRODUCTION}

It is increasingly recognised that the phenotype of mothers matters for population productivity and resilience to environmental change in the sea (Birkeland \& Dayton 2005, Hsieh et al. 2006, Venturelli et al. 2009). Specifically, large and old females of many aquatic species are typically highly fecund and are known to produce larger, more robust offspring as compared to small and young spawners (Trippel 1998, Berkeley et al. 2004a). Furthermore, offspring size and viability may increase with maternal physiological condition (McCormick 1998). In conflict with this knowledge, fisheries typically remove large and old individuals, leading to 'longevity overfishing', i.e. a rather newly defined form of overfishing (Berkeley et al. 2004b, Beamish et al. 2006). This contradiction clearly represents a challenge to the management of harvested marine species (Francis et al. 2007).

Although maternal influences on offspring size are quite well documented in many fishes (e.g. Chambers \& Leggett 1996), less is known about such effects in decapod crustaceans. This is unfortunate since decapods are popular target species in recreational and commercial fisheries throughout the world, and often show clear signs of overharvesting (Spanier \& Lavalli 1998, Guzman \& Tewfik 2004, Melville-Smith \& de Lestang 2006, Agnalt et al. 2007). A progressive decline in size at maturity over time has been documented for both sexes in the western rock lobster Panulirus 
cygnus, which forms the basis of a valuable fishery in Western Australia (Melville-Smith \& de Lestang 2006). In some American lobster Homarus americanus populations, egg size is a function of female size, with larger females producing larger eggs with higher energetic content (Attard \& Hudon 1987, Sibert et al. 2004). Similarly, in the European lobster Homarus gammarus, both fecundity and egg size increase with maternal size (Tully et al. 2001, Agnalt et al. 2008). In this species, there is also some evidence that maternal size may have a positive effect on offspring survival, as measured under semi-natural conditions during the early benthic phase (Jørstad et al. 2005). However, the mechanisms linking maternal influences on egg size to larval size and viability in the European lobster are still unclear, and could involve competitive interactions and cannibalism prior to and during settlement, as well as starvation resistance during the early pelagic stages.

Furthermore, the link between maternal size and the variation in offspring size is, to our knowledge, poorly understood. Most studies on maternal influences in aquatic organisms tend to focus on mean values of sibling traits, i.e. levels of within-species or among-population variation in offspring size (Brooks et al. 1997, Marshall \& Keough 2008). From a theoretical perspective, sibling size variation could be due to either inaccurate trait expression (e.g. physiological constraints) or adaptation to environmental unpredictability (i.e. bet-hedging), although the topic is under strong discussion and the sparseness of available empirical data seems to preclude any general conclusions (Fox \& Czesak 2000, Einum \& Fleming 2004). Recently, Marshall et al. (2008) sought to bring the theories together and suggested that selection will act on both the mean and the variance of offspring size: 'In an unpredictable environment where the range of viable offspring sizes is narrow, selection is likely to favour the production of variable offspring sizes. In contrast, when the environment is relatively stable and there is a broad range of viable offspring sizes, selection is likely to favour a constant offspring size within broods'. From a practical perspective, our understanding of decapod life histories would benefit from quantitative estimates of how females partition their reproductive investment among offspring, and whether this partition scales with the size of the mother.

Here, we study maternal influences on offspring size variation and viability in wild European lobsters from the Norwegian Skagerrak coast. Historically, the Skagerrak region has supported a viable population of lobsters, but catches have plummeted over the past 30 to $40 \mathrm{yr}$ (Agnalt et al. 2007). The stock is currently red listed as near threatened according to the IUCN (International Union for Conservation of Nature) criteria (Oug et al. 2006). Specifically, we test for the effects of maternal size on mean egg size as well as on the variation in egg size. We also quantify to what extent larval size scales with maternal size and egg size. Lastly, we report on a laboratory experiment testing whether maternal influence on offspring size affects individual larval fitness (measured as starvation resistance) during the early pelagic stage.

\section{MATERIALS AND METHODS}

Ovigerous European lobsters were supplied by fishers operating in coastal waters in the Risør area $\left(58^{\circ} 43^{\prime} \mathrm{N}, 9^{\circ} 17^{\prime} \mathrm{E}\right)$ on the Norwegian Skagerrak coast during October 2005 and $2006\left(\mathrm{n}_{2005}=14\right.$, mean carapace length $(C L)=99.6 \mathrm{~mm}$, range: 79 to $152 \mathrm{~mm}$; $\mathrm{n}_{2006}=31, \mathrm{CL}=98.7 \mathrm{~mm}$, range: 85 to $140 \mathrm{~mm}$ ). The lobsters were held indoors in 2 green fibreglass holding tanks ( $3 \mathrm{~m}$ diameter $\times 1 \mathrm{~m}$ water depth, 8:16 h light: dark cycle) at the Institute of Marine Research aquarium facility in Flødevigen, Arendal. Aerated seawater was supplied from a $75 \mathrm{~m}$ intake pipe nearby, reflecting the natural seasonal conditions in the region during the period up to hatching after 7 to 8 mo of incubation. In 2005-2006, mean incubation temperature was $8.4^{\circ} \mathrm{C}$ (range: 5.7 to $12.9^{\circ} \mathrm{C}$ ), and mean salinity was 34.2 (range: 33.7 to 34.9 ); in 2006-2007, mean temperature was $9.0^{\circ} \mathrm{C}$ (range: 5.8 to $13.8^{\circ} \mathrm{C}$ ), and mean salinity was 34.0 (range: 33.2 to 34.7 ). The exchange rate was maintained at a level where the entire water volume was changed every $4 \mathrm{~h}$. The lobsters were fed daily with frozen shrimp or krill. Lobsters were inspected daily as eggs approached hatching, and lobsters with mature eggs were transferred to a hatchery raceway system. In this system, the lobsters where held separately in wooden flow-over chambers $(0.5 \times 0.5 \times 0.5 \mathrm{~m}$, water depth of $0.45 \mathrm{~m}$ ), which were designed to deliver hatched larvae into sieving cassettes that were inserted into downstream chambers of equal dimensions. Water was supplied from the $75 \mathrm{~m}$ intake pipe, aerated and heated to $15^{\circ} \mathrm{C}$ by a heat exchanger in both years. Lobsters were not fed during the hatching of eggs to avoid potential contamination of larvae. After the hatching of all eggs, lobsters were returned to the larger holding tanks. Hatching of individual eggs lasted for up to $1 \mathrm{wk}$. The first hatching occurred on 25 May 2006 and 11 April 2007. The last hatching began on 10 July 2006 and 28 July 2007. The extended hatching period reflects the fact that we could neither control the extrusion dates, nor the degree-days accumulated prior to capture. Further, we observed no trend between female size and hatching date.

Egg size was quantified as egg dry weight (DW), which is a good approximation of the energy invested by the mother into individual offspring (Attard \& 
Hudon 1987). For this purpose, a sample of 50 eggs was collected from each female during incubation in February in both years. The eggs were processed immediately after collection. Forty eggs from each female were separated and dried at $50^{\circ} \mathrm{C}$ for $24 \mathrm{~h}$. The eggs were stored in airtight containers until weighing, and 30 eggs from each female were individually weighed to the nearest $0.01 \mathrm{mg}$ with a microbalance (Mettler MT5). Measurement error was $0.01 \mathrm{mg}$, based on 10 measurements of 1 egg (mean $=1.529 \pm 0.00316 \mathrm{mg} \mathrm{SD}$, range: 1.52 to $1.53 \mathrm{mg}$ ). Agnalt (2008) reported that egg DW did not vary throughout the incubation period. However, an earlier study showed that DW was reduced during embryo development, with only a slight reduction throughout most of the development period, followed by a more rapid decrease towards the end of development (Pandian 1970). In February 2006 and 2007, no females had eggs with embryos in development stages beyond Stage II, as defined by Pandian (1970), in which DW is only minutely reduced.

Larval size was quantified as the CL of Stage I larvae, which was measured to the nearest $0.05 \mathrm{~mm}$ using a dissecting microscope with an ocular scale. Each larva was placed in a position where the ocular scale projected an axis through the middle of the right eye to the posterior margin of the carapace. CL was measured as the distance from the posterior eye margin to the posterior margin of the carapace along this axis. For this purpose, 10 larvae were collected within $12 \mathrm{~h}$ of hatching from 9 females (covering the full range of maternal sizes). The larvae were preserved in $70 \%$ ethanol prior to measurement.

Larval survival in the absence of food was quantified from 20 Stage I larvae that were collected within $12 \mathrm{~h}$ of hatching from each of 11 females in 2006 (i.e. females supplied by fishers in October 2005), and from each of 30 females in 2007 (i.e. females supplied by fishers in October 2006). Each larva was placed in a transparent Perspex tube $(120 \mathrm{~mm}$ long $\times 50 \mathrm{~mm}$ inside diameter), with a $1 \mathrm{~mm}$ mesh being secured with tight fitting PVC rims at both ends. The mesh retained the larvae but allowed exchange of water. The containers had a round Styrofoam 'life-saver' that kept tubes floating in a vertical position, with an internal water depth of $\sim 9 \mathrm{~cm}$ from the surface to the mesh bottom. All containers were released within one common semicircular tank ( $2 \mathrm{~m}$ diameter $\times 0.2 \mathrm{~m}$ water depth). Seawater was supplied horizontally along the side of the tank close to the water surface level, ensuring circular water movement and movement of individual Perspex tubes containing larvae. This experimental design was originally developed by Haugen \& Vøllestad (2000) in order to randomise the effects of any microscale environmental variation, i.e. to obtain a 'common garden' rearing regime. The exchange rate was maintained at
$81 \mathrm{~min}^{-1}$. Water was supplied from the $75 \mathrm{~m}$ intake pipe, aerated and heated to $15^{\circ} \mathrm{C}$ by a heat exchanger in both years. Temperature regulation was semi-automated but varied somewhat, and was therefore measured daily along with salinity. Mean temperature was $15.4 \pm 0.3$ and $14.9 \pm 0.5^{\circ} \mathrm{C} \mathrm{SD}$ in 2006 and 2007, respectively. Mean salinity was $33.9 \pm 0.1$ and $33.8 \pm$ $0.2 \mathrm{SD}$ in 2006 and 2007, respectively. We inferred that this water source did not contain suitable food organisms for newly hatched lobster larvae and chose not to filter the water. No visible organisms were observed in the tank or in individual containers during the careful daily visual inspection of larvae throughout the experiment in both years. Moreover, no marine larvae settled in the tank throughout the experiment in both years. We checked all larvae for mortality and metamorphosis daily and kept track of individuals using a tagging system in which coded flags were pinned to the Styrofoam 'lifesaver' of each individual container. Each batch of larvae was given a letter code with no direct reference to the mother to ensure an unbiased inspection routine. Larvae were considered dead when they were opaque or when no movement of the abdomen or appendages was observed within $30 \mathrm{~s}$ of close visual inspection. Only 3 researchers were involved in the checking of larvae (in both years) in order to standardise the procedure. The experiment lasted from 25 May to 26 July (63 d) in 2006 and from 11 April to 11 August (123 d) in 2007. As we had no means of synchronising the hatching time for different females, we introduced batches of larvae into the experiment as they hatched, and made daily measurements of potentially variable environmental conditions (temperature and salinity). Up to 80 individual containers with larvae were held in the common garden tank simultaneously.

We used classical linear models (McCullagh \& Nelder 1999) to analyse maternal influences on offspring size. Maternal size, i.e. CL was ln-transformed in order to stabilise the variance, and residual plots indicated that the models fitted the data adequately. We first tested for the effect of maternal CL (MCL) on mean egg DW using the following model structure:

$$
\mathrm{DW}_{i j}=\beta_{0}+\beta_{1}\left(\ln \left(\mathrm{MCL}_{i j}\right)\right)+\beta_{j}+\varepsilon_{i j}
$$

where $\beta_{0}$ is the intercept, $\beta_{1}$ is the slope relating to the ln-transformed MCL, $\beta_{j}$ is a year-specific offset, and $\varepsilon_{i j}$ is the error term. Next, we tested for the effect of MCL on the coefficient of variation $(\mathrm{CV}=\mathrm{SD} /$ mean) in sibling dry weight using the same model structure as in Eq. (1):

$$
\mathrm{CV}_{\mathrm{ij}}=\beta_{0}+\beta_{1}\left(\ln \left(\mathrm{MCL}_{i j}\right)\right)+\beta_{j}+\varepsilon_{i j}
$$

In addition to egg size, we also tested for the effect of MCL on larval carapace length (LCL):

$$
\mathrm{LCL}_{i}=\beta_{0}+\beta_{1}\left(\mathrm{MCL}_{i}\right)+\varepsilon_{i}
$$


where $\varepsilon_{i}$ is the error term. Lastly, we tested for the effect of mean egg DW on mean LCL:

$$
\mathrm{LCL}_{i}=\beta_{0}+\beta_{1}\left(\mathrm{DW}_{i}\right)+\varepsilon_{i}
$$

where $\beta_{1}$ is the slope relating to mean egg DW.

Larval survival was measured in days and analysed by fitting a generalised additive model (GAM) to the data. GAMs are an extension of generalised linear models (GLMs) that allow flexible nonparametric effects of covariates on the response variable of interest (Hastie \& Tibshirani 1990), and we hypothesised possible nonlinear effects on survival. Recognising that temporal variation in hatching time among females precluded a perfect common-garden experimental setup, we sought to correct for the effects of batch-specific variation in rearing regime in the statistical analyses. Specifically, we included mean batch-specific water temperature, salinity and mean day of the year (which could account for an additional unexplained temporal variation) as covariates in the model:

$$
S_{i}=\beta_{0}+\mathrm{g}_{1}\left(\mathrm{DW}_{i}\right)+\mathrm{g}_{2}\left(T_{i}\right)+\mathrm{g}_{3}\left(\mathrm{Sal}_{i}\right)+\mathrm{g}_{4}\left(D_{i}\right)+\varepsilon_{i}
$$

where $S$ is the mean larval survival for each mother, and gs are smoothing functions (i.e. natural cubic splines) linking egg DW, water temperature $(T)$, salinity (Sal) and day of the year $(D)$ to the response variable. A residual plot indicated that this model fitted the data adequately. Preliminary analysis showed no detectable effect of year on survival; thus, this parameter was not considered further. Model selection was based on the generalised cross validation (GCV) score, which measures the compromise between the roughness and smoothness of a fitted curve (Wood 2000).

\section{RESULTS}

Mean egg DW among females ranged from 1.023 to $1.772 \mathrm{mg}(1.469 \pm 0.027 \mathrm{mg} \mathrm{SE})$ and increased significantly with increasing MCL (Fig. $1 \mathrm{a} ; \beta_{0}=-1.99 \pm$ $0.63 \mathrm{SE}, \beta_{1}=0.74 \pm 0.14 \mathrm{SE}, \mathrm{p}<0.001$, model $\mathrm{R}^{2}=0.43$ ). For a given $\mathrm{MCL}$, mean egg DW was significantly higher in 2007 than in $2006\left(\beta_{j}=0.11 \pm 0.04 \mathrm{SE}, \mathrm{p}=\right.$ 0.016). Sibling size variation among females, which was measured as the CV of egg DW, ranged from 0.027 to $0.090(0.047 \pm 0.002 \mathrm{SE})$ and decreased significantly with increasing MCL (Fig. $1 \mathrm{~b} ; \beta_{0}=26.14 \pm 5.68 \mathrm{SE}, \beta_{1}=$ $-0.045 \pm 0.012 \mathrm{SE}, \mathrm{p}<0.001$, model $\mathrm{R}^{2}=0.26$ ). For comparison, sibling size variation measured as the SD of egg DW also decreased with increasing $\mathrm{MCL}_{\text {, al- }}$ though this relationship was not statistically significant at the 0.05 level (slope: $-2.624 \times 10^{-5} \pm 1.687 \times 10^{-5} \mathrm{SE}$, $\mathrm{p}=0.127$ ). For a given $\mathrm{MCL}$, sibling size variation $(\mathrm{CV})$ was marginally lower in 2007 than in $2006\left(\beta_{j}=-0.008\right.$ $\pm 0.004 \mathrm{SE}, \mathrm{p}=0.056$ ).
Mean LCL among females ranged from 2.38 to $2.69 \mathrm{~mm}(2.53 \pm 0.03 \mathrm{~mm} \mathrm{SE})$ and increased significantly with increasing MCL (Fig. 1c; $\beta_{0}=2.14 \pm$ $0.08 \mathrm{SE}, \beta_{1}=0.004 \pm 0.001 \mathrm{SE}, \mathrm{p}=0.00193$, model $\mathrm{r}^{2}=$ $0.74)$. Mean LCL also increased significantly as a function of mean egg DW (Fig. $1 d_{i} \beta_{0}=1.79 \pm 0.08 \mathrm{SE}, \beta_{1}=$ $0.50 \pm 0.05 \mathrm{SE}, \mathrm{p}<0.001$, model $\mathrm{r}^{2}=0.92$ ).

In the starvation experiment, mortality was generally low during the first 5 to $10 \mathrm{~d}$ and then increased sharply. No larvae survived beyond $19 \mathrm{~d}$ (Fig. 2). Mean survival for a batch of 20 larvae from each female ranged from 8.05 to $13.5 \mathrm{~d}$ (overall mean $=11.44 \pm$ $0.19 \mathrm{~d}$ SE). No larvae had sufficient energy reserves to reach metamorphosis to the next instar (Stage II). Larval survival was best described with a GAM containing additive effects of mean egg DW, mean salinity and mean day of the year. Visual inspection of this model showed that the effects of salinity and day of the year were close to linear. Therefore, these effects were set as parametric linear effects in the final model, for ease of presentation. There was evidence for a weak (but significant) nonlinear effect of mean egg DW on mean survival (Fig. $3 ; p=0.049$, model $\mathrm{R}^{2}=0.41$ ). The available data suggests a positive effect of egg size on larval survival up to an intermediate egg weight of $\sim 1.4 \mathrm{mg}$. Above this value, the effect levelled out and showed signs of reversal. However, the data provided only weak support for this pattern, since the CI overlapped with 0 for egg weights greater than $\sim 1.1 \mathrm{mg}$ (Fig. 3). Moreover, the overall effect of egg size on larval survival was no longer significant ( $p=0.18$ ) when the female with the smallest eggs was removed from the data set. Survival increased significantly with increasing salinity $\left(\beta_{\mathrm{Sal}}=3.84 \pm 1.23 \mathrm{SE}, \mathrm{p}=0.004\right)$ and decreased significantly throughout the duration of the study $\left(\beta_{D}=-0.022 \pm 0.0053 \mathrm{SE}, \mathrm{p}<0.001\right)$. There was no evidence for an additional effect of water temperature on survival ( $p=0.92)$; however, evidence for a weak negative effect was noted when both salinity and day of the year were excluded as covariates $\left(\beta_{T}=\right.$ $-1.19 \pm 0.60 \mathrm{SE}, \mathrm{p}=0.05$ ). This reflects a partial confounding between covariates, where temperature tended to increase throughout the study.

\section{DISCUSSION}

Our study demonstrates complex maternal influences in the European lobster where female body size influences both the mean and the variability in offspring size. We also show a connection between egg size and larval size and, possibly, early larval survival. Egg size increased significantly with maternal body size. This finding is in concordance with previous work conducted on European lobsters in other regions (Tully 

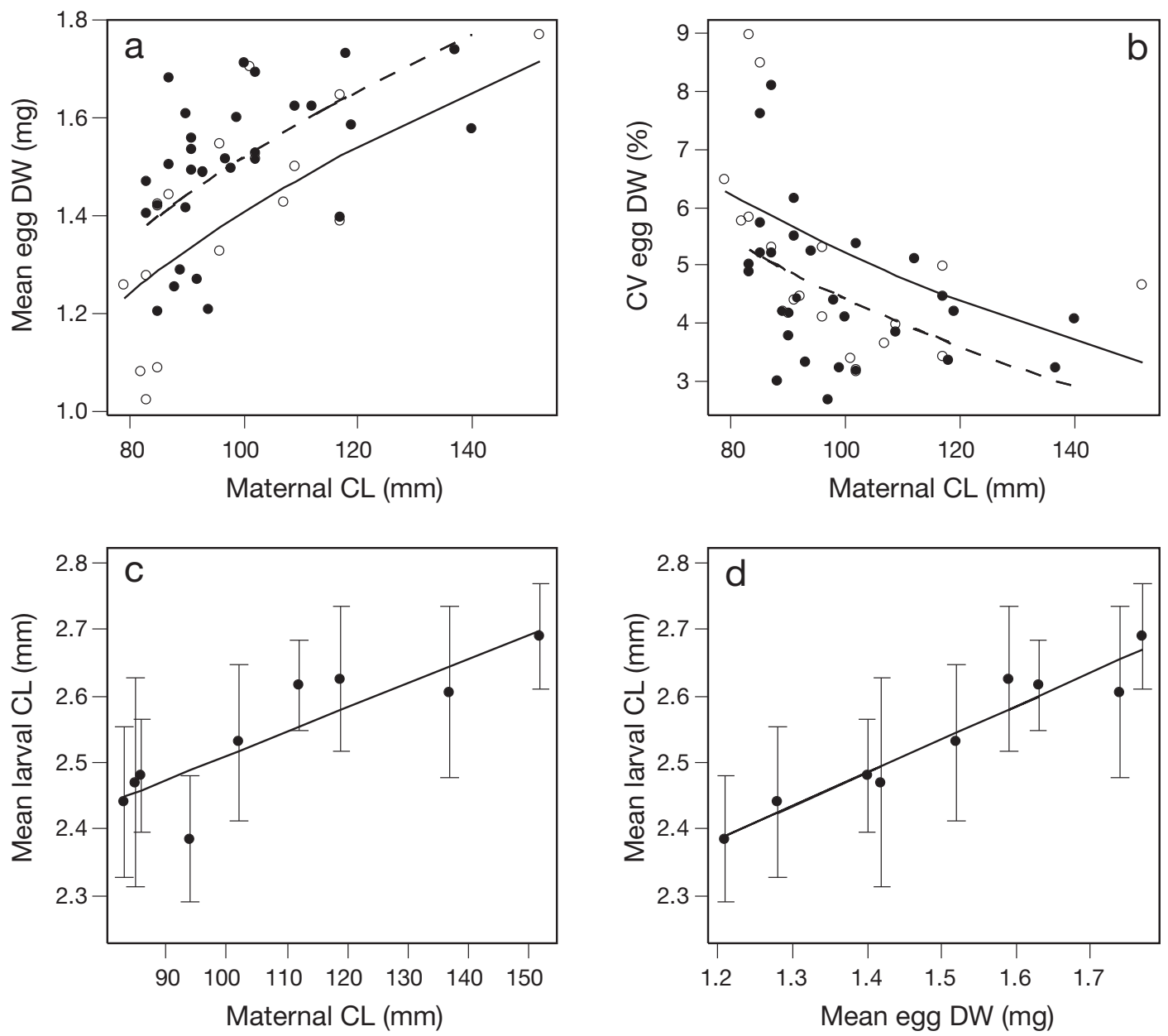

Fig. 1. Homarus gammarus. Relationship between (a) offspring size (mean egg dry weight, DW) and maternal size (carapace length, CL); (b) sibling size variation (measured as the coefficient of variation, CV in egg DW) and maternal CL; (c) mean larval CL and maternal CL; and (d) mean larval CL and mean egg DW in wild European lobsters from the Norwegian Skagerrak coast. Open circles in (a) and (b): females collected in $2005(\mathrm{n}=14)$; filled circles in (a) and (b): females collected in 2006 ( $\mathrm{n}=31$ ); solid and stippled trend lines in (a) and (b): slopes fitted to 2005 and 2006 data, respectively; whiskers in (c) and (d): \pm SD

et al. 2001, Jørstad et al. 2005, Agnalt et al. 2008). In addition, we document that egg size is closely linked to larval size, implying that egg size (measured as DW) is a good approximation of offspring size. A similar relationship was observed in the American lobster Homarus americanus in certain areas of its range (Attard \& Hudon 1987, Ouellet \& Plante 2004).

Life history theory offers several plausible explanations why offspring size is positively correlated to female size in the European lobster. Sakai \& Harada (2001) suggested simply that if larger mothers can provision their young more efficiently than smaller ones, this could result in a correlation between maternal and offspring size. Parker \& Begon (1986) predicted that if competition between siblings is likely, then larger, more fecund mothers should produce larger offspring to compensate for increased levels of competition. Currently, we lack information regarding the scales of competition that occurs between siblings in species with dispersive larvae. However, planktotrophic sibling larvae in European lobsters are probably more likely to encounter each other than non-siblings, especially during the initial stage of their dispersal. Furthermore, there could potentially be competition among siblings during the brooding phase, e.g. for oxygen. Hendry et al. (2001) suggested that if the maternal phenotype influences the quality of the natal environment (e.g. larger lobster mothers releasing their larvae in a favourable depth and current), then a correlation between offspring and maternal size should be anticipated. On the other hand, the maternal size-offspring size relationship may be non-adaptive and may instead be a product of anatomical scaling constraints (Fox \& Czesak 2000) (see below). At present, we lack information for European lobsters to distinguish between these explanatory models. 


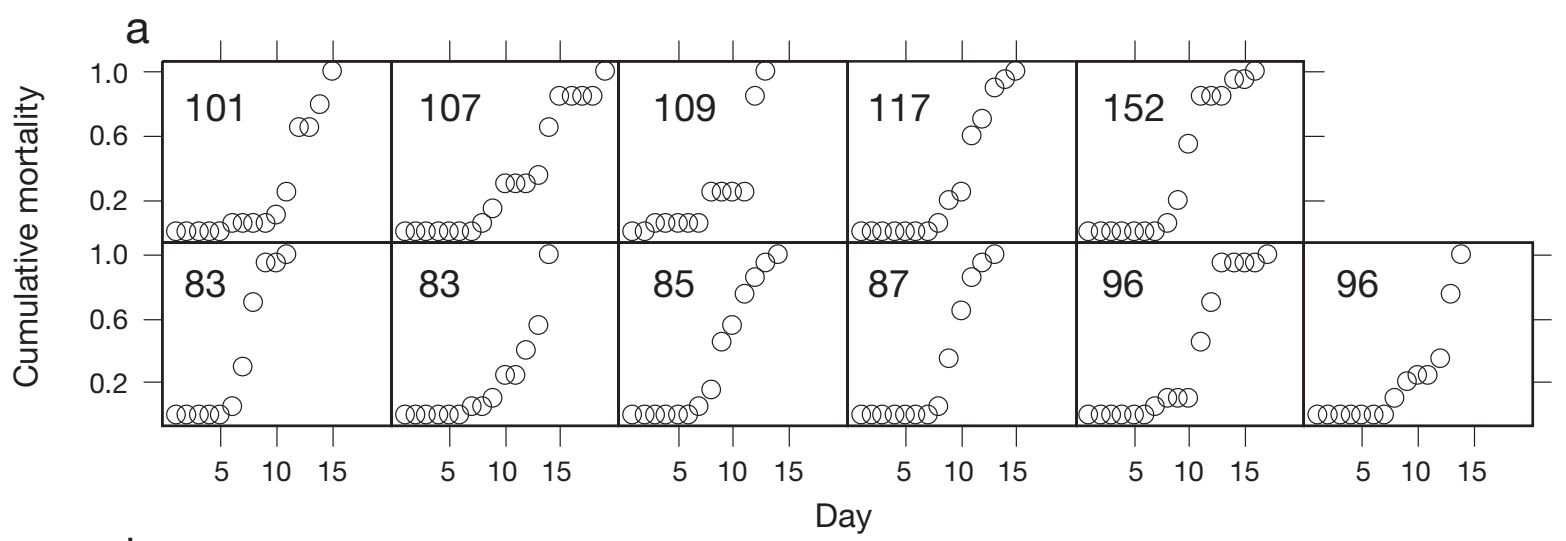

b

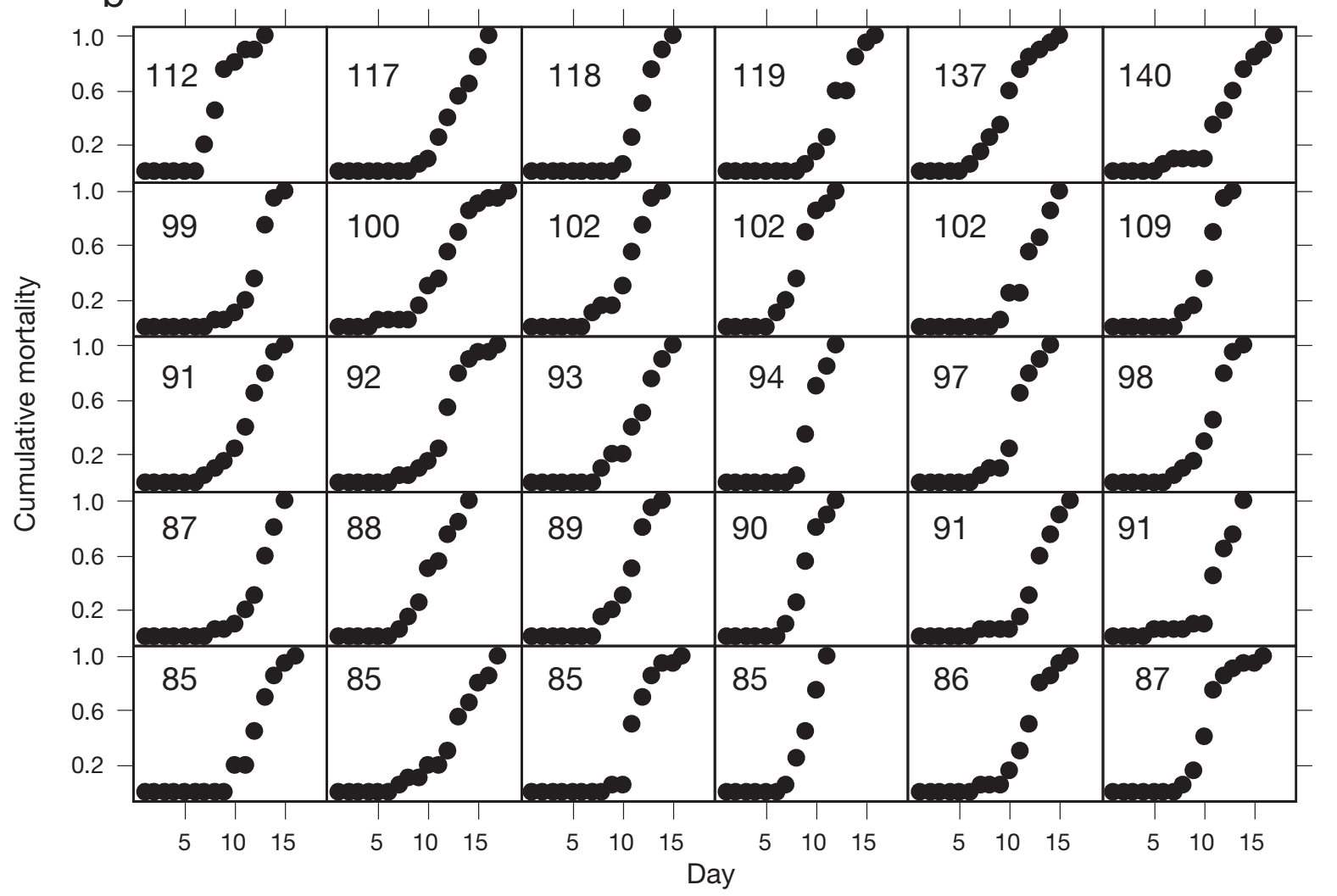

Fig. 2. Homarus gammarus. Cumulative mortality of larvae from 41 wild-caught females from the Norwegian Skagerrak coast. Larvae hatched from females collected in (a) $2005(\mathrm{n}=11)$ and (b) $2006(\mathrm{n}=30)$ and reared in individual containers until expiry in the absence of food. Maternal carapace length in $\mathrm{mm}$ is indicated in each panel

Sibling size variation decreased with increasing maternal size in our study. In general, large females produced large and evenly sized siblings, while small females produced small and more variable siblings. We know of no other study on decapods that examined maternal influence on sibling size variation. However, Marshall et al. (2000) found a similar effect of maternal size on variation in egg size within broods in the ascidian Pyura stolonifera. A recent study on the brown trout Salmo trutta L. found no effect of maternal size on sibling size variation (Gregersen et al. 2009). One possible explanation for this result is that sibling size variation primarily represents inaccurate trait expression rather than evolutionary adaptation (Fox \& Czesak 2000, Einum \& Fleming 2004), where smaller females are more constrained and less precise in their production of offspring. In Homarus species, moulting occurs less frequently as individuals grow older and larger. Smaller females will moult between each egg extrusion (spawning), whereas larger females (>120 mm CL) 


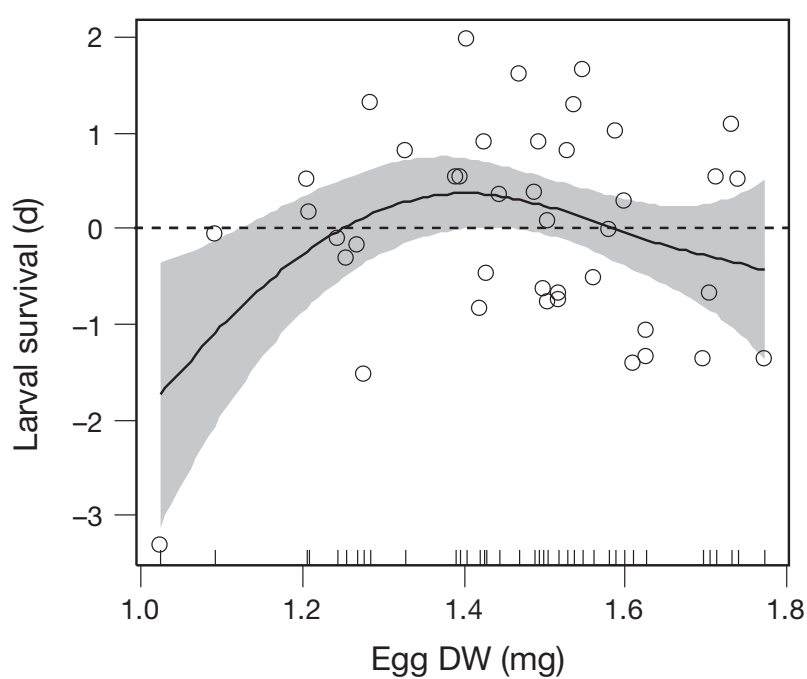

Fig. 3. Homarus gammarus. Relationship between mean larval survival (shown as anomalies) and mean egg size (egg dry weight, DW) in European lobster from the Norwegian Skagerrak coast. Offspring were sampled from 41 wildcaught berried females that were reared in captivity until hatching. Shaded area: $95 \%$ CI around the mean prediction (solid line); scatterplot shows the partial residuals (open circles); dotted line indicates zero effect of egg DW on larval survival and tick marks above the $x$-axis represent observed mean egg DW

are likely to extrude eggs in consecutive seasons within the same moult stage (Waddy et al. 1995, Agnalt et al. 2007). These size-specific differences in the moult cycle, where smaller females are forced to partition energy between egg production and more frequent moults, may be an important constraining factor in offspring production. Alternatively, maternal influences on offspring size variation may also represent adaptive transgenerational phenotypic plasticity (Marshall \& Uller 2007). This would somehow imply that smaller female lobsters maximise fitness by producing relatively variable offspring, as compared to larger females. The underlying mechanism for such a strategy is unclear, but suggests that offspring from small females tend to face a less predictable environment than those from large females.

The variation in egg size among similar-sized small females could potentially be related to their physiological condition and/or previous growth history (McCormick 1998, Olsen \& Vøllestad 2003). Some of this variation may also be genetic, since egg size is known to be a heritable trait in some aquatic organisms (e.g. $\mathrm{Su}$ et al. 1997).

Our experimental work revealed a weak but significant relationship between egg mass and larval resistance to starvation. This relationship was not linear. Instead, the available data indicate that survival time increased from the smallest to intermediate-sized offspring, with no further increase for the upper half of the size range (see Fig. 3). We note, however, that data is sparse at each extreme end of egg sizes, and that 1 female with particularly small eggs had a clear influence on the result. Therefore, we cannot conclude about the effect of egg size on larval survival in our experiment. Nevertheless, our study appears to agree with 2 earlier studies on maternal influences in decapods: (1) Jørstad et al. (2005) found that juvenile survival (measured at the early benthic stage) in the European lobster was higher for large mothers that produce large eggs as compared to small females, and (2) Giménez \& Torres (2002) reported that a high initial biomass at hatching was associated with high levels of reserves in advanced larval stages in the estuarine crab Chasmagnathus granulata, and attributed this to an enhanced ability of larger larvae to capture and ingest prey (Pepin et al. 1992). Hatching time had a significant effect on survival in our experiment, with a decrease in larval survival throughout the study in both years. This may indicate that a later hatching date, which in turn may indicate a longer incubation time, causes more energy to be used by embryos prior to hatching.

Clearly, there is scope for future studies addressing maternal influences on the early life history of the European lobster. A future study that includes a starvation experiment would benefit from having a parallel feeding experiment. In addition to acting as a control, it would enable testing of the hypothesis that maternal influences are only expressed, or are expressed more strongly, when per capita resource availability is low.

Our findings illuminate considerable differences in reproductive strategy among female Homarus gammarus throughout their size range, particularly differences pertaining to offspring size and within-brood size variation. Maternal influences on offspring size could be an important source of variation in larval quality and, consequently, of variation in recruitment (Marshall \& Keough 2008, Venturelli et al. 2009). Therefore, maternal influences could also be an important source of error in fisheries science and management if they are assumed to be absent or unimportant.

Our study suffers somewhat from the fact that the European lobster has been subjected to longevity overfishing, i.e. we are unable to observe maternal influences throughout a size range that is not truncated by harvesting. This may have biased the maternal influences that we measured towards low values. Future studies should aim to sample egg size and measure female body size and growth consecutively throughout their life histories in areas where lobsters are protected from fishing, i.e. in marine reserves. 
Acknowledgements. We thank the lobster fishers of Risør for providing the ovigerous lobsters used in this study; K. Kristiansen and I. Bernardes for laboratory assistance; and G. P. Jones for valuable comments on an earlier version of this manuscript. We also thank 4 anonymous reviewers for thoughtful reviews that greatly improved the manuscript. This work is part of E.M.'s PhD thesis on the ecology and demography of the European lobster, which was financed by the Norwegian Research Council (project no. 173432/S40).

\section{LITERATURE CITED}

Agnalt AL (2008) Fecundity of the European lobster (Homarus gammarus) off southwestern Norway after stock enhancement: Do cultured females produce as many eggs as wild females? ICES J Mar Sci 65:164-170

Agnalt AL, Kristiansen TS, Jørstad KE (2007) Growth, reproductive cycle, and movement of berried European lobsters (Homarus gammarus) in a local stock off southwestern Norway. ICES J Mar Sci 64:288-297

Attard J, Hudon C (1987) Embryonic development and energetic investment in egg production in relation to size of female lobster (Homarus americanus). Can J Fish Aquat Sci 44:1157-1164

Beamish RJ, McFarlane GA, Benson A (2006) Longevity overfishing. Prog Oceanogr 68:289-302

Berkeley SA, Chapman C, Sogard SM (2004a) Maternal age as a determinant of larval growth and survival in a marine fish, Sebastes melanops. Ecology 85:1258-1264

Berkeley SA, Hixon MA, Larson RJ, Love MS (2004b) Fisheries sustainability via protection of age structure and spatial distribution of fish populations. Fisheries (Bethesda, Md) 29:23-32

Birkeland C, Dayton PK (2005) The importance in fishery management of leaving the big ones. Trends Ecol Evol 20: 356-358

Brooks S, Tyler CR, Sumpter JP (1997) Egg quality in fish: What makes a good egg? Rev Fish Biol Fish 7:387-416

Chambers RC, Leggett WC (1996) Maternal influences on variation in egg sizes in temperate marine fishes. Am Zool 36:180-196

Einum S, Fleming IA (2004) Environmental unpredictability and offspring size: conservative versus diversified bethedging. Evol Ecol Res 6:443-455

> Fox CW, Czesak ME (2000) Evolutionary ecology of progeny size in arthropods. Annu Rev Entomol 45:341-369

Francis RC, Hixon MA, Clarke ME, Murawski SA, Ralston S (2007) Fisheries management - ten commandments for ecosystem-based fisheries scientists. Fisheries (Bethesda) $32: 217-233$

Giménez L, Torres G (2002) Larval growth in the estuarine crab Chasmagnathus granulata: the importance of salinity experienced during embryonic development, and the initial larval biomass. Mar Biol 141:877-885

Gregersen F, Vøllestad LA, Olsen EM, Haugen TO (2009) Sibling-size variation in brown trout in relation to egg size and stream size. J Fish Biol 74: 1259-1268

Guzman HM, Tewfik A (2004) Population characteristics and co-occurrence of three exploited decapods (Panulirus argus, $P$. guttatus and Mithrax spinosissimus) in Bocas del Toro, Panama. J Shellfish Res 23:575-580

Hastie TJ, Tibshirani RJ (1990) Generalized additive models. Chapman \& Hall, London

Haugen TO, Vøllestad LA (2000) Population differences in early life-history traits in grayling. J Evol Biol 13:897-905

Hendry AP, Day T, Cooper AB (2001) Optimal size and num- ber of propagules: allowance for discrete stages and effects of maternal size on reproductive output and offspring fitness. Am Nat 157:387-407

> Hsieh CH, Reiss CS, Hunter JR, Beddington JR, May RM, Sugihara G (2006) Fishing elevates variability in the abundance of exploited species. Nature 443:859-862

> Jørstad KE, Prodöhl PA, Kristiansen TS, Hughes M and others (2005) Communal larval rearing of European lobster (Homarus gammarus): family identification by microsatellite DNA profiling and offspring fitness comparisons. Aquaculture 247:275-285

> Marshall DJ, Keough MJ (2008) The evolutionary ecology of offspring size in marine invertebrates. In: Advances in marine biology, Vol 53. Elsevier Academic Press, San Diego, CA, p 1-60

> Marshall DJ, Uller T (2007) When is a maternal effect adaptive? Oikos 116:1957-1963

> Marshall DJ, Styan CA, Keogh MJ (2000) Intraspecific covariation between egg and body size affects fertilization kinetics of free-spawning marine invertebrates. Mar Ecol Prog Ser 195:305-309

Marshall DJ, Bonduriansky R, Bussière LF (2008) Offspring size variation within broods as a bet-hedging strategy in unpredictable environments. Ecology 89:2506-2517

McCormick MI (1998) Behaviourally induced maternal stress in a fish influences progeny quality by a hormonal mechanism. Ecology 79:1873-1883

McCullagh P, Nelder JA (1999) Generalized linear models. Chapman \& Hall/CRC, London

> Melville-Smith R, de Lestang S (2006) Spatial and temporal variation in the size at maturity of the western rock lobster Panulirus cygnus George. Mar Biol 150:183-195

Olsen EM, Vøllestad LA (2003) Microgeographical variation in brown trout reproductive traits: possible effects of biotic interactions. Oikos 100:483-492

Ouellet P, Plante F (2004) An investigation of the sources of variability in American lobster (Homarus americanus) eggs and larvae: female size and reproductive status, and interannual and interpopulation comparisons. J Crustac Biol 24:481-495

Oug E, Djursvoll P, Aagaard K, Brattegaard T and others (2006) Crustacea. In: Kålås JA, Viken Å, Bakken TS (eds) Norwegian red list. Artsdatabanken, Trondheim, p 197-206

> Pandian TJ (1970) Ecophysiological studies on the developing eggs and embryos of the European lobster Homarus gammarus. Mar Biol 5:154-167

> Parker GA, Begon M (1986) Optimal egg size and clutch size: effects of environment and maternal phenotype. Am Nat 128:573-592

Pepin P, Shears TH, Delafontaine Y (1992) Significance of body size to the interaction between a larval fish (Mallotus villosus) and a vertebrate predator (Gasterosteus aculeatus). Mar Ecol Prog Ser 81:1-12

Sakai S, Harada Y (2001) Why do large mothers produce large offspring? Theory and a test. Am Nat 157:348-359

> Sibert V, Ouellet P, Brethes JC (2004) Changes in yolk total proteins and lipid components and embryonic growth rates during lobster (Homarus americanus) egg development under a simulated seasonal temperature cycle. Mar Biol 144:1075-1086

- Spanier E, Lavalli KL (1998) Natural history of Scyllarides latus (Crustacea: Decapoda): a review of the contemporary biological knowledge of the Mediterranean slipper lobster. J Nat Hist 32:1769-1786

> Su GS, Liljedahl LE, Gall GAE (1997) Genetic and environmental variation of female reproductive traits in rainbow 
trout (Oncorhynchus mykiss). Aquaculture 154:115-124

Trippel EA (1998) Egg size and viability and seasonal offspring production of young Atlantic cod. Trans Am Fish Soc 127:339-359

Tully O, Roantree V, Robinson M (2001) Maturity, fecundity and reproductive potential of the European lobster (Homarus gammarus) in Ireland. J Mar Biol Assoc UK 81: 61-68

> Venturelli PA, Shuter BJ, Murphy CA (2009) Evidence for har-

Editorial responsibility: Romuald Lipcius,

Gloucester Point, Virginia, USA vest-induced maternal influences on the reproductive rates of fish populations. Proc Biol Sci 276:919-924

Waddy S, Aiken DE, de Kleijn DPV (1995) Control of growth and reproduction. In: Factor JR (ed) Biology of the lobster Homarus americanus. Academic Press, New York, NY, p 217-265

Wood SN (2000) Modelling and smoothing parameter estimation with multiple quadratic penalties. J R Stat Soc Ser B. Stat Methodol 62:413-428

Submitted: February 9, 2009; Accepted: November 1, 2009 Proofs received from author(s): January 27, 2010 